\title{
The efficiency of the hotel industry in Singapore
}

\begin{abstract}
Existing literature related to evaluating the efficiency of the hotel industry, generally, uses different types of radial Data Envelopment Analysis (DEA) to compare the relative efficiency of different hotels in a location. This research note has adopted a different approach by treating years as decision making units (DMUs). This will allow policymakers to evaluate the relative efficiency of a hotel industry as a whole over a specified time period so that the effects of the occurrence of events on the efficiency of hotel industry can be evaluated. This study focuses on the efficiency of hotel industry in Singapore from 1995 to 2010. The analysis is carried out using the non-radial DEA called the Slacks-Based Measure (SBM) to identify the efficient years. Then the efficient DMUs are ranked with the SBM model of super-efficiency.
\end{abstract}

Keyword: Non-radial data envelopment analysis; Slacks-based measure; Hotel industry. 